This is a PDF file of an unedited manuscript that has been accepted for publication in Journal of Cleaner Production:

The manuscript will undergo copyediting, typesetting, and review of the resulting proof before it is published in its final form. Please note that during the production process errors may be discovered which could affect the content, and all legal disclaimers that apply to the journal pertain. The final version will be available at:

https://doi.org/10.1016/j.jclepro.2015.05.086

\title{
Applying Multi-Criteria Decision Analysis to the Life-Cycle Assessment of Vehicles
}

\section{Ana Rita Domingues ${ }^{a}$, Pedro Marques ${ }^{b}$, Rita Garcia ${ }^{\text {b }}$, Fausto Freire ${ }^{\mathrm{b}}$ and Luís C. Dias ${ }^{\mathrm{a}, \mathrm{c}, *}$}

${ }^{\mathrm{a}}$ INESC Coimbra

Rua Antero de Quental, n. ${ }^{\circ} 199,3000-033$ Coimbra, Portugal

Emails: arsd@fct.unl.pt, lmcdias@fe.uc.pt

${ }^{\mathrm{b}}$ ADAI-LAETA

Departamento de Engenharia Mecânica, Universidade de Coimbra

Pólo II Campus, Rua Luís Reis Santos, 3030-788 Coimbra, Portugal

Emails: pedro.marques@dem.uc.pt, rita.garcia@dem.uc.pt, fausto.freire@dem.uc.pt

${ }^{\mathrm{c}}$ Faculdade de Economia, Universidade de Coimbra

Av. Dias da Silva 165, 3004-512 Coimbra, Portugal

*Corresponding author. Tel.: +351239 790558; fax: +351 239403511

\begin{abstract}
This article presents a methodology to classify light-duty vehicles according to their environmental impacts. The classification is based on Life-Cycle Impact Assessment indicators and vehicle operation indicators, which are aggregated using a Multi-Criteria Decision Analysis (MCDA) method. In contrast with most literature combining Life-Cycle Assessment (LCA) and MCDA, vehicles are not compared directly; they are compared to pre-established profiles defining a set of classes. These profiles are established relatively to the impacts of the country's light-duty fleet. The ELECTRE TRI method is chosen for MCDA classification, thus avoiding complete substitutability among criteria and allowing for imprecision in the data. MCDA typically incorporates the subjective values of decision makers, namely through criteria weighting. To obtain conclusions that are not contingent on a given weight vector, we consider a space of weight vectors defined by constraints with a clear rationale and obtain all the possible results compatible with those constraints. The methodology is applied to classify six vehicles available in Portugal with different powertrains: Gasoline and Diesel Internal Combustion Vehicles, Plug-in Hybrid Electric Vehicles (10 and 40-mile battery range) and Battery Electric Vehicle. The discussion suggests how this methodology might be useful for a decision-making entity that wishes to classify vehicles according to their environmental impacts.
\end{abstract}

Keywords: Environmental indicators, Life-Cycle Impact Assessment (LCIA), Normalization, Multi-Criteria Decision Analysis (MCDA), ELECTRE TRI, Light-duty vehicles. 
Acronyms: AC - Acidification; AD - Abiotic Depletion; BEV - Battery Electric Vehicle; EUT Eutrophication; FC - Fuel Consumption (primary energy); FU - Functional Unit (FU); GW Global Warming; HEV - Hybrid Electric Vehicle; LCA - Life-Cycle Assessment; LCIA - LifeCycle Impact Assessment; MCDA - Multi-Criteria Decision Analysis; OLD - Ozone Layer Depletion; PHEV - Plug-in Hybrid Electric Vehicles; PM - Particulate Matter; PO - Photochemical Oxidation

\section{Introduction}

Vehicles are one of the main causes of air pollution in urban areas, mostly due to fossil fuel combustion during vehicle operation. Many countries have established measures to control air pollution from transport, such as limiting vehicle speed and banning older vehicles (e.g. older than EURO 1) from city centers. The dependence of the transportation sector on fossil fuel imports is also a political concern in many countries, such as Portugal. Aiming to promote the reduction of pollution and oil imports, the European Union (EU) Directive 2009/28/EC (European Comission, 2009) set a target of $10 \%$ share of energy from renewable sources in transportation by 2020. Electric vehicles are being promoted (e.g., by tax incentives) since they can have an important role in achieving this target due to their use of electricity, if it is generated with a large share of renewable sources. In countries such as Portugal, another important benefit can be the reduction of oil imports.

The assessment of the environmental impacts of vehicles is an important component of the decision-making process of policy makers and consumers. A meaningful assessment of alternative vehicles, especially when these are based on different technologies, should address multiple dimensions of environmental performance and include impacts over all stages of the vehicle lifecycle using a Life-Cycle Assessment (LCA) (Arena et al., 2013). Indeed, several studies have assessed the environmental performance of new vehicles both at product or company level using a life-cycle approach (Liu et al., 2014; Ma et al., 2012; Nanaki and Koroneos, 2013; Ou et al., 2012; Samaras and Meisterling, 2008; Smith, 2010; van Vliet et al., 2011; Yagcitekin et al., 2013). Most of these studies assess the environmental impacts of conventional and alternative powertrains, such as electric or hybrid, in different locations, e.g. China (Liu et al., 2014; Ou et al., 2012), Greece (Nanaki and Koroneos, 2013), Turkey (Yagcitekin et al., 2013) and the UK (Ma et al., 2012). These studies highlight the importance of LCA to avoid burden shifting, i.e., reducing a negative impact at one part of the system but increasing the same impact elsewhere. However, these studies usually focus on few environmental impact categories (indicators), such as Global Warming (GW), not accounting for many other potentially relevant impacts (Hawkins et al., 2012). In particular, few studies covered impacts specifically associated with the operation phase, in which lie the main differences between new and conventional vehicle alternatives, despite the importance of this phase with regard to air pollution in urban areas.

The need to consider multiple environmental impacts suggests the use of Multi-Criteria Decision Analysis (MCDA). MCDA has been defined as a "collection of formal approaches which seek to 
take explicit account of multiple criteria in helping individuals or groups explore decisions that matter" (Belton and Stewart, 2002, p. 2). Tsoukiàs (2007) presents MCDA as a process encompassing the activities of representing the problem situation (describing the purpose of the process and the actors concerned), choosing a problem formulation model (stating the problem situation in a formal way), building an evaluation model (specifying alternatives to be evaluated and how they are evaluated), and applying this model to derive recommendations (translating the results to the current language of the client actors).

Recent developments in MCDA applications to LCA have highlighted that the use of MCDA contributes to support environmental decisions consistent with the values of the decision-maker (Kiker et al., 2005) by aggregating complex information and being able to cope with qualitative and quantitative data in a transparent way (Jeswani et al., 2010). MCDA is particularly useful in environmental decision making because it can compare alternatives regarding technical information, stakeholder values and non-monetary factors (Huang et al., 2011). Using MCDA it is possible to incorporate multiple perspectives in an assessment, namely in the final weighting phase (Rogers and Seager, 2009; Soares et al., 2006).

MCDA and LCA complement each other well (Geldermann and Rentz, 2005; Hermann et al., 2007; Myllyviita et al., 2012; Seppälä et al., 2002), but there are still relatively few studies combining these methods. Examples in the transportation sector include studies on transportation systems (Bouwman and Moll, 2002), vehicle fuels (Mohamadabadi et al., 2009; Rogers and Seager, 2009; Tan et al., 2004; Zhou, 2007), biofuel pathways (Narayanan et al., 2007; Perimenis et al., 2011), and road maintenance strategies (Elghali et al., 2006). All these authors use MCDA methods that rank the alternatives, such as weighted sums and additive value functions (Bouwman and Moll, 2002; Elghali et al., 2006; Zhou, 2007), the Analytic Hierarchy Process (Narayanan et al., 2007), PROMETHEE and SMAA-LCIA (Mohamadabadi et al., 2009; Prado-Lopez et al., 2014; Rogers and Seager, 2009), compromise programming (Tan et al., 2004), or a custom-built method in the case of Perimenis et al. (2011).

In this article we contribute to this literature complementing it in a number of ways. We propose and apply a methodology to classify light-duty vehicles available in Portugal according to their environmental impacts. Vehicles with different powertrains (Gasoline and Diesel vehicles, Plug-in Hybrid Electric vehicles and Battery Electric vehicle) are used as diverse examples. Thus, unlike other works (Mohamadabadi et al., 2009; Rogers and Seager, 2009; Tan et al., 2004; Zhou, 2007), we are assessing specific existing vehicles rather than fuels.

In Portugal, as in many European countries, vehicles are classified for taxation purposes, but the classes are defined based only on use phase $\mathrm{CO}_{2}$ emission ranges. This article aims to address not only GW impacts but also other indicators, some considering the whole life-cycle of the vehicle and others focused on the use phase.

In terms of MCDA formulation, this work deals with a sorting problem (Roy, 1996; Zopounidis and Doumpos, 2002): the vehicles are to be sorted (classified) according to a predefined set of classes, taking into account a set of environmental impact indicators. Such classes are in this case ordered from the highest to the lowest environmental impact. The aim of obtaining an absolute evaluation of each alternative distinguishes this work from most literature on the combined use of LCA and 
MCDA, which uses relative evaluation methods that aim at selecting one alternative, or ranking the alternatives, rather than assigning them to performance classes. Let us also note that a different type of classification might be performed, namely using a classification matrix (Dangelico and Pontrandolfo, 2010).

Among several possible sorting methods (Zopounidis and Doumpos, 2002), this work uses ELECTRE TRI (Yu, 1992), which is a classic sorting method within the ELECTRE family (Figueira et al., 2005; Roy, 1991). In contrast with methods referred to above such as weighted sums, ELECTRE methods have several important characteristics: they can work with any type of scales, the criteria weights are scale-independent, they allow for imprecision in performance indicators and they deny full substitutability (it is a so-called non-compensatory method) (Figueira et al., 2005; Infante et al., 2013; Khalili and Duecker, 2013). The latter characteristic means that in ELECTRE, if the decision maker wishes so, a very poor performance on one indicator cannot be compensated by a very good performance on another indicator. As far as the authors are aware, this work is the first one applying ELECTRE TRI in a combined LCA and MCDA methodology.

This work also differs from most literature on the way criteria (in this research, environmental indicators) weights are dealt with. Indeed, besides the analyst's methodological choices at each stage of the process, MCDA introduces subjectivity explicitly through the incorporation of criteria weighting (Rowley et al., 2012). Rather than selecting precise criteria weight vectors or a small number of variants, which is the most common choice in the literature (e.g., Santoyo-Castelazo and Azapagic, 2014) (an exception is Rogers and Seager, 2009), we consider a space of weight vectors defined by constraints with a clear rationale and obtain all the possible results compatible with those constraints. The constraints are such that they can be easily understood and accepted by decision makers, since they do not involve value judgment that could be considered unwarranted.

The details on the methodology are presented next in Section 2. Section 3 presents various scenarios of stakeholder preferences and the respective results, aiming at obtaining conclusions that are robust, i.e., not contingent on precise criteria weights. The results are discussed in the concluding section, suggesting how the methodology proposed in this article might be useful for a decisionmaking entity that wishes to classify vehicles according to their environmental impacts. Although the methodology is illustrated for only six vehicles and considering the Portuguese context, it is applicable to other vehicles and regions.

\section{Material and methods}

The conceptual framework for this work is presented in Figure 1 and is further detailed in sections 2.1-2.3. Section 2.1 provides detailed information about the light-duty vehicles that were chosen as examples, which are vehicles available in the Portuguese market (intending to illustrate, but not represent, different vehicle technologies). This section also describes the life-cycle and use-phase indicators used as evaluation criteria by the classification method. Section 2.2 proposes a means to normalize the indicator scales. Although this step is optional for the chosen classification method, ELECTRE TRI, it can contribute to a better appraisal of the significance of impact results, which facilitates setting the parameters of ELECTRE TRI (namely the definition of classes). Section 2.3 
describes the ELECTRE TRI method in detail (the reasons for choosing this method were explained in the introduction).

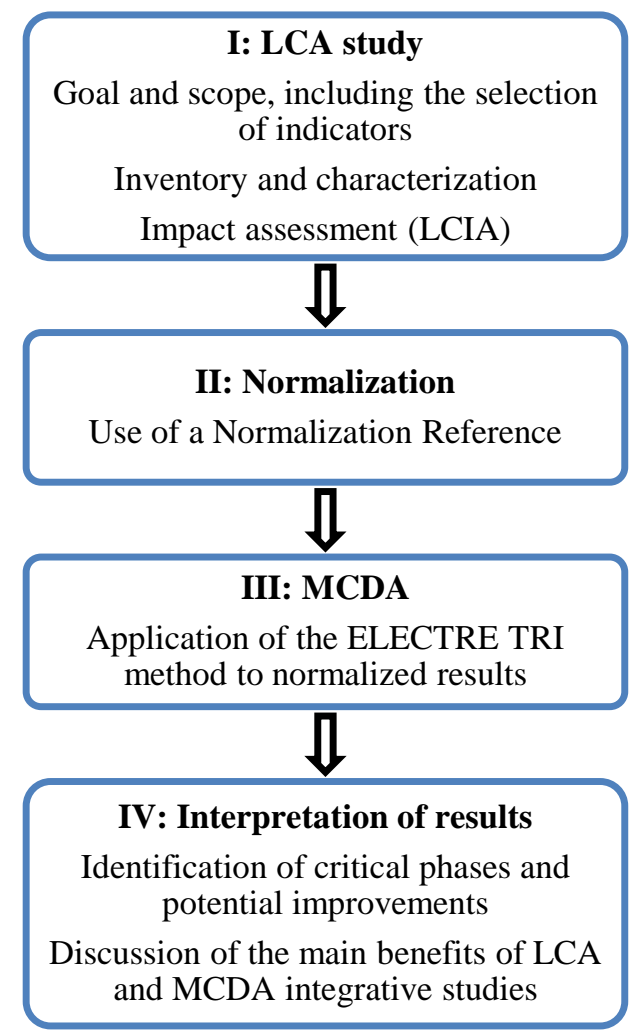

Figure 1. Methodology to assess the impacts of vehicles.

\subsection{LCA model, goal and scope}

LCA was applied to assess potential environmental impacts of six EURO 5 compact passenger vehicles (light-duty vehicles) available in Portugal, comparable in terms of size and power: a Gasoline Internal Combustion Engine Vehicle, a Diesel Internal Combustion Engine Vehicle, a Hybrid Electric Vehicle (HEV), a Plug-in Hybrid Electric Vehicle 10-mile battery range (PHEV10), a Plug-in Hybrid Electric Vehicle 40-mile battery range (PHEV40), and a Battery Electric Vehicle (BEV). A vehicle service life of $200000 \mathrm{~km}$ was assumed. The main characteristics of the vehicle alternatives are summarized in Table 1. All data presented is based on real vehicles available in Portugal. A 15\% increase in real-world fuel and electricity consumption factors compared to reported New European Driving Cycle (NEDC) figures (DAT, 2014) was assumed, according to the TREMOVE model (Ceuster et al., 2007). The HEV and both PHEVs use gasoline in their internal combustion engines. 
Table 1. Vehicle alternatives: main characteristics.

\begin{tabular}{|c|c|c|c|c|c|c|}
\hline Vehicle specifications & ${ }_{5}$ Gasoline $^{1,}$ & Diesel $^{1,5}$ & $\mathrm{HEV}^{1,2,5}$ & ${ }_{5}$ PHEV10 $0^{1,3,}$ & PHEV40 ${ }^{1,3,5}$ & $\mathrm{BEV}^{1,4,5}$ \\
\hline Engine displacement $\left(\mathrm{cm}^{3}\right)$ & 1395 & 1598 & 1798 & 1798 & 1398 & n.a. \\
\hline Consumption $(1 / 100 \mathrm{~km}) \mid(\mathrm{kWh} / 100 \mathrm{~km})^{5}$ & $5.4 \mid$ n.a. & $4.3 \mid$ n.a. & $4.6 \mid$ n.a. & $2.4 \mid 6.0$ & $1.4 \mid 15.0$ & n.a. $\mid 17.3$ \\
\hline Weight of vehicle (battery included) (kg) & 1270 & 1295 & 1500 & 1525 & 1732 & 1660 \\
\hline Battery type & n.a. & n.a. & $\mathrm{NiMH}$ & $\mathrm{LiFePO}_{4}$ & $\mathrm{LiFePO}_{4}$ & $\mathrm{LiMn}_{2} \mathrm{O}_{4}$ \\
\hline Battery capacity $(\mathrm{kWh})$ & n.a. & n.a. & 1.3 & 4.4 & 16 & 24 \\
\hline Weight of battery $(\mathrm{kg})$ & n.a. & n.a. & 36 & 46 & 197 & 300 \\
\hline Battery range (full discharge) $(\mathrm{km})$ & n.a. & n.a. & n.a. & 16 & 64 & 175 \\
\hline $\begin{array}{l}\text { n.a.: not applicable } \\
{ }^{1} \text { (DAT, 2014) } \\
{ }^{2} \text { (Samaras and Meisterling, 2008) } \\
{ }^{3} \text { (Zackrisson et al., 2010); Combined consu } \\
{ }^{4} \text { (Notter et al., 2010) } \\
{ }^{5} \text { Consumption values based on NEDC figu } \\
\text { 2007). }\end{array}$ & $\begin{array}{l}\text { ption of } \mathrm{g} \\
\text { plus } 15 \%\end{array}$ & $\begin{array}{l}\text { soline an } \\
\text { to reflect }\end{array}$ & $\begin{array}{l}\text { lectricity } \\
\text { al-world }\end{array}$ & nsumptior & tors (Ceus & et al., \\
\hline
\end{tabular}

The model considered the overall life-cycle of vehicles and their components (e.g. batteries), as well as the electricity generation system and the production of fossil fuels (gasoline and diesel), from a cradle-to-grave perspective. The Functional Unit (FU) selected was $1 \mathrm{~km}$ driving distance. The data and inventory presented in this article was based on previous LCA research on vehicles and electricity generation in Portugal, by Freire and Marques (2012), Marques et al. (2013) and Garcia et al. (2014). The main sources of data were peer-reviewed literature and the ecoinvent v2.2 database (Spielmann et al., 2007). Specific data for the Portuguese context was used whenever possible, including the specific characteristics of the vehicles available in Portugal (see Table 1), the Portuguese electricity mix for 2011 (Garcia et al., 2014), and the Portuguese passenger vehicle fleet (Garcia and Freire, 2013; Garcia et al., 2015). Battery inventories were adapted from Notter et al. (2010) for $\mathrm{LiMn}_{2} \mathrm{O}_{4}$ batteries, Zackrisson et al. (2010) for $\mathrm{LiFePO}_{4}$ batteries and Samaras and Meisterling (2008) for NiMH batteries.

The inventory data was characterized into the following indicators, according to the CML 2001 LCIA method (Guinée et al., 2002): Abiotic Depletion (AD), Acidification (AC), Eutrophication (EUT), Global Warming (GW), Ozone Layer Depletion (OLD), and Photochemical Oxidation (PO). Additional indicators addressed vehicle operation: Fuel Consumption (primary energy) (FC) and tailpipe and abrasion emissions $\left(\mathrm{NO}_{\mathrm{x}}, \mathrm{CO}\right.$, Particulate Matter - $\left.\mathrm{PM}\right)$, since the use phase was considered important in the comparison of vehicles. These additional indicators intend to reflect concerns about oil dependency (fuel consumption in vehicle operation) and pollution in cities (tailpipe and tire abrasion emissions).

\subsection{Normalization}

The results of the LCIA and vehicle operation indicators can be normalized using Normalization References (NR). NR are important to convey LCA results (Kim et al., 2012) because they reflect the relative performance (significance) of alternatives (Finnveden et al., 2002). 
Two types of normalization techniques can be applied to express the significance of impact results: internal (or case-specific) normalization, and external normalization or determination of relative contribution (Dahlbo et al., 2012; Gaudreault et al., 2009).

Heijungs et al. (2007) and Prado-Lopez et al. (2014) discuss several issues associated with external normalization as typically understood, that is, considering as a reference system the worldwide impacts or the impacts of a population of a specific area, in a certain year. Using such references may be useful to reveal the magnitude of the impacts in a broader context. However, it might introduce biases when the LCIA category indicators of the system being studied do not match exactly the indicators of the reference system. This may result from some data being included in one system but missing from the other, missing characterization factors for certain substances, spatial and temporal variability, mismatch between the boundary of the reference and studied systems, and the existence of outdated references. Internal normalization does not have these issues. It typically consists in using the highest and lowest impacts of different alternatives being compared as references to transform the original scales into $[0,1]$ ranges. However, for many MCDA methods, this raises the bias of dependence on other alternatives: adding or removing one alternative may change the relative positions of the remaining alternatives (Dias and Domingues, 2014). The choice of normalization can have an important impact on the results, as shown by Myllyviita et al. (2014) and Prado-Lopez et al. (2014). Prado-Lopez et al. (2014) suggest another approach to avoid the use of an external reference system, the use of SMAA-LCA, which is a method that does not require scale transformations.

Normalization is often used to prepare results for additional procedures, such as weighting (ISO, 2006), but it is not required by ELECTRE TRI. Nevertheless, normalization was performed in this study as a means to facilitate the communication with stakeholders, in particular decision makers, by providing a well-defined and recognizable reference system. It consisted in representing the impact of the alternatives with respect to the emissions of a reference fleet. The reference values consist in the average fleet impacts calculated for the 2011 Portuguese (PT) light-duty fleet, which is the reference scenario in this article.

Considering that $x_{n}$ is the normalized result, $x$ the indicator value and $x_{\text {ref }}$ the reference value, indicators were normalized according to the following equation:

$$
x_{n}=\frac{x}{x_{\text {ref }}}
$$

The NR values used are listed in Table 2. Let us note that the criteria weights are independent of any normalization in the MCDA method applied in this work.

Typically, there is no alternative that is superior to all other on all the indicators. The next phase of the study consisted in the application of the MCDA method (in this case ELECTRE TRI) to perform the aggregation of the normalized results for each vehicle. 
Table 2. Normalization reference: 2011 PT light-duty fleet average impacts per km. Values were calculated based on the model described in Garcia and Freire (2013) and Garcia et al. (2015), which considers the stock of vehicles and the age and activity level (distance travelled) of the vehicles by powertrain in the Portuguese fleet.

\begin{tabular}{|c|c|}
\hline Indicators & Impacts per $\mathrm{km}$ \\
\hline AD: Abiotic depletion (g Sb eq) & 1.55 \\
\hline AC: Acidification ( $\mathrm{g} \mathrm{SO}_{2}$ eq) & 0.70 \\
\hline EUT: Eutrophication ( $\mathrm{g} \mathrm{PO}_{4}$ eq) & 0.13 \\
\hline GW: Global warming ( $\mathrm{g} \mathrm{CO}_{2}$ eq) & 232.16 \\
\hline OLD: Ozone layer depletion (g CFC-11 eq) & $2.75 \times 10^{-5}$ \\
\hline PO: Photochemical oxidation $\left(\mathrm{g} \mathrm{C}_{2} \mathrm{H}_{4} \mathrm{eq}\right)$ & 0.06 \\
\hline FC: Fuel consumption $\left(\mathrm{MJ}_{\text {prim }}\right)$ & 2.81 \\
\hline $\mathrm{NO}_{\mathrm{x}}(\mathrm{g})$ & 0.27 \\
\hline $\mathrm{CO}(\mathrm{g})$ & 1.10 \\
\hline PM: Particulate matter (g) & 0.11 \\
\hline
\end{tabular}

\subsection{MCDA: ELECTRE TRI}

ELECTRE TRI (Yu, 1992) is a multiple criteria sorting method. Rather than comparing alternatives against each other to determine a ranking or a winner, sorting methods intend to evaluate each alternative on its own merits to determine its performance class among a set of classes defined beforehand. This type of classification in performance classes (e.g., number of stars, rating classes, energy efficiency labels) is common nowadays to summarize information about the qualities of an alternative in an easy to understand format.

To describe the details of ELECTRE TRI, the following notation will be used (Dias and Mousseau, 2003; Roy, 1991):

- $G=\left\{g_{l}(),. \ldots, g_{n}().\right\}$ denotes the set of $n$ evaluation criteria. In this paper, these correspond to impacts to be minimized.

- $A=\left\{a_{1}, \ldots, a_{m}\right\}$ denotes a set of $m$ alternatives to be sorted;

- $B=\left\{b^{0}, \ldots, b^{k}\right\}$ denotes the set of profiles that define a set of $k$ classes, $\left\{C^{l}, \ldots, C^{k}\right\}$. Each class $C^{h}$ $(h=1, \ldots, k)$ is defined through two reference profiles: a lower bound $b^{h-1}$ and an upper bound $b^{h}$. By convention, let $C^{l}$ denote the worst class and $C^{k}$ denote the best class. Figure 2 depicts how the classes are defined by the level of the reference profiles on the multiple criteria.

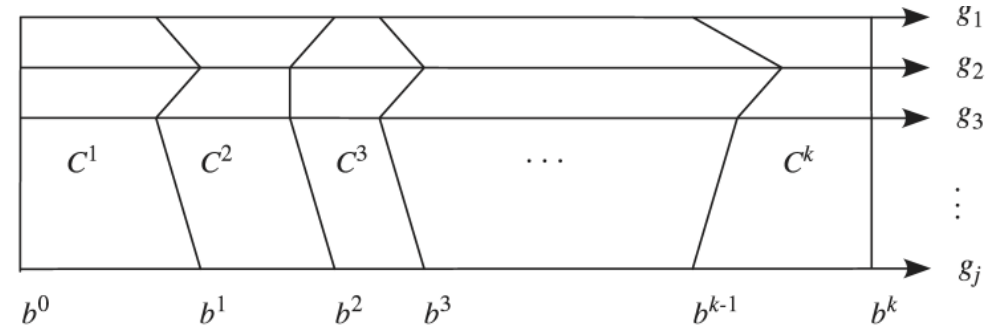

Figure 2. Definition of classes using profiles.

For each criterion $(j=1, \ldots, n)$ : 
- $q_{j}$ is a parameter denoting the indifference threshold for criterion $g_{j}($.$) : two levels of$ performance are considered to be indistinguishable if their difference is $q_{j}$ or less.

- $\quad p_{j}$ is a parameter denoting the preference threshold for criterion $g_{j}($.$) : one level of performance$ is considered to be undoubtedly better than another one if their difference is $p_{j}$ or more; together with indifference thresholds, this allows modelling how imprecision in performance indicators is taken into account.

- $\quad v_{j}$ is a parameter denoting the veto threshold for criterion $g_{j}($.$) : if an alternative is much worse$ than the reference profile (by a difference greater than $v_{j}$ ) according to $g_{j}($.$) , this criterion$ vetoes the conclusion that the alternative is at least as good as the profile (even if it is very good in other criteria, this difference cannot be compensated);

- $\quad w_{j}$ is a parameter denoting the weight (voting power) of criterion $g_{j}($.$) ; by convention, weights$ are non-negative numbers and their sum is equal to 1 .

- $\quad c_{j}\left(a_{i}, b^{h}\right)$ is a computed index that indicates how much $g_{j}($.$) agrees that a_{i}$ outranks (i.e. is at least as good as) $b^{h}$, on a scale from 0 (does not agree) to 1 (fully agrees):

$$
c_{j}\left(a_{i}, b^{h}\right)=\left\{\begin{array}{cc}
0, & \text { if } g_{j}\left(b^{h}\right)-g_{j}\left(a_{i}\right)<-p_{j} \\
\left(g_{j}\left(b^{h}\right)-g_{j}\left(a_{i}\right)+p_{j}\right) /\left(p_{j}-q_{j}\right), & \text { if }-\mathrm{p}_{j} \leq g_{j}\left(b^{h}\right)-g_{j}\left(a_{i}\right)<-q_{j} \\
1, & \text { if } g_{j}\left(b^{h}\right)-g_{j}\left(a_{i}\right) \geq-q_{\mathrm{j}}
\end{array}\right.
$$

- $d_{j}\left(a_{i}, b^{h}\right)$ is a computed discordance index that indicates how much $g_{j}($.$) disagrees with the$ assertion that $a_{i}$ outranks $b^{h}$, on a scale from 0 (no discordance at all) to 1 (fully disagrees):

$$
d_{j}\left(a_{i}, b^{h}\right)=\left\{\begin{array}{cc}
0, & \text { if } g_{j}\left(b^{h}\right)-g_{j}\left(a_{i}\right)>-p_{j} \\
\left(-g_{j}\left(b^{h}\right)+g_{j}\left(a_{i}\right)-p_{j}\right) /\left(v_{j}-p_{j}\right), & \text { if }-\mathrm{v}_{j} \leq g_{j}\left(b^{h}\right)-g_{j}\left(a_{i}\right)<-p_{j} \\
1, & \text { if } g_{j}\left(b^{h}\right)-g_{j}\left(a_{i}\right) \leq-v_{\mathrm{j}}
\end{array}\right.
$$

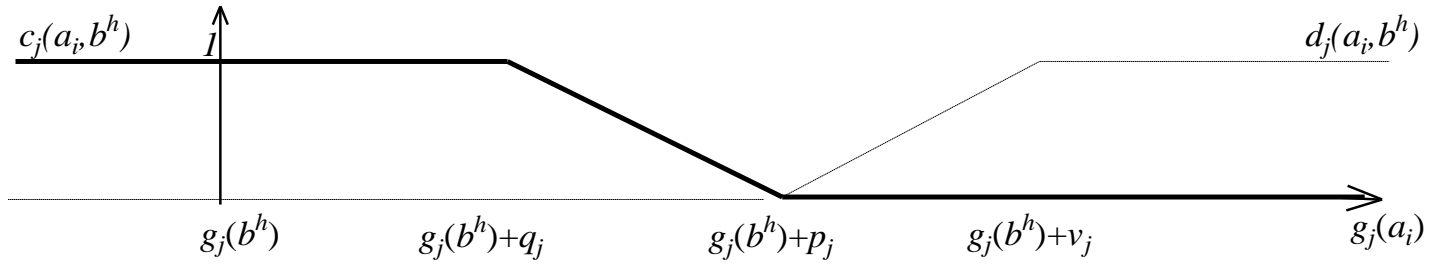

Figure 3. Concordance and discordance functions.

Figure 3 depicts the concordance and discordance functions. Finally,

- $c\left(a_{i}, b^{h}\right)$ is a computed concordance index that indicates the global concordance with the assertion that $a_{i}$ outranks $b^{h}$, taking into account the weight ("voting power") of each criterion:

$$
c\left(a_{i}, b^{h}\right)=\sum_{j=1}^{n} w_{j} c_{j}\left(a_{i}, b^{h}\right)
$$


- $s\left(a_{i}, b^{h}\right)$ is a computed index that indicates the overall credibility of the assertion that $a_{i}$ outranks $b^{h}$, summarizing the arguments for and against it, on a scale from 0 to 1 :

$$
s\left(a_{i}, b^{h}\right)=c\left(a_{i}, b^{h}\right) \cdot\left[1-\max _{j \in\{1, \ldots, n\}} d_{j}\left(a_{i}, b^{h}\right)\right]
$$

According to this formula, if $d_{j}\left(a_{i}, b^{h}\right)$ is close to or equal to one on any of the criteria, then the credibility will necessarily be low, even if the global concordance is high.

- $\quad \lambda$ is a cutting level parameter denoting the required majority level to warrant an outranking conclusion: $a_{i}$ outranks $b^{h}$ if only if $s\left(a_{i}, b^{h}\right) \geq \lambda$. For instance, setting $\lambda=0.51$ means that in the absence of veto a simple weighted majority of the criteria (considering their weights) is sufficient to conclude $a_{i}$ outranks $b^{h}$. Setting for instance $\lambda=0.67$ makes it more difficult for $a_{i}$ to outrank $b^{h}$, since now one requires that the criteria in favor of the outranking represent at least $67 \%$ of the total weight of the criteria.

ELECTRE TRI has two variants. The most demanding variant is used in this work: an alternative is sorted into $C^{1}$ if it is not good enough to outrank $b^{1}$, it is sorted into $C^{2}$ if it is good enough to outrank $b^{1}$ but not good enough outrank $b^{2}$, and so on. An outranking assertion holds if its credibility attains (or exceeds) the required cutting level $\lambda$. Thus, the classification rule is the following:

$$
a_{i} \text { is classified in class } C^{h} \text { if and only if } s\left(a_{i}, b^{h-1}\right) \geq \lambda \text { and } s\left(a_{i}, b^{h}\right)<\lambda \text {. }
$$

In this work, the ELECTRE TRI parameters were set as described next:

Initially we consider six classes (another possibility will be discussed in Section 3.4). These classes correspond to the impacts of the alternative relatively to the reference scenario (2011 PT light-duty fleet average impacts per $\mathrm{km}$ ), based on the 10 indicators presented in Table 2 . The six classes are: $\mathrm{C}^{1}=$ "much worse than the reference scenario", $\mathrm{C}^{2}=$ "worse than the reference scenario", $\mathrm{C}^{3}=$ "similar, but slightly worse than the reference scenario", $\mathrm{C}^{4}=$ "similar, but slightly better than the reference scenario", $C^{5}=$ "better than the reference scenario" and $C^{6}=$ "much better than the reference scenario". We consider that the reference profiles require the same normalized performance for all the indicators: $g_{j}\left(b^{5}\right)=0.5, g_{j}\left(b^{4}\right)=0.8, g_{j}\left(b^{3}\right)=1, g_{j}\left(b^{2}\right)=1.2$, and $g_{j}\left(b^{l}\right)=1.5$ $(j=1, \ldots, n)$ define the boundaries of the classes (there is no need to explicitly define $b^{0}$ and $\left.b^{6}\right)$. Thus, if for instance an alternative has less than half of the reference scenario emissions, on some indicator, then this indicator "votes", according to its weight, to place the alternative in class $C^{6}$. Let us note that normalization was optional. Working with the original scales would be possible, setting for instance for indicator $\mathrm{AD}, g_{1}\left(b^{5}\right)=0.5 \times 1.55, g_{1}\left(b^{4}\right)=0.8 \times 1.55, g_{1}\left(b^{3}\right)=1.55$, etc. For indicator AC we would set $g_{2}\left(b^{5}\right)=0.5 \times 0.70$, and so on.

The computation of the concordance indices $c_{j}\left(a_{i}, b^{h}\right)$ considers $q_{j}=0$ and $p_{j}=0.1$ for all the criteria $j=1, \ldots, n$. Thus, one level of performance is considered to be undoubtedly better than another one if their difference is $10 \%$ of the average fleet emissions or more. If the difference is lower, there is a gradual transition from no concordance to full concordance. 
Concerning discordance indices, we obtained results with and without veto thresholds. Veto thresholds (when used) concern only the ability to reach $C^{6}$, setting $v_{j}=g_{j}\left(b^{l}\right)-g_{j}\left(b^{l}\right)=1(j=1, \ldots, n)$. This means that an impact 50\% higher than the reference scenario in any of the indicators prevents the alternative from being sorted in the best class, even if it has good performances in all other indicators.

The credibility of an outranking assertion is considered to be sufficient when the credibility index is at least as high as the cutting level $\lambda(\lambda \in[0.5,1])$. In this study, different cutting levels were considered, namely $\lambda=0.51$ (simple majority), $\lambda=0.67$ ( $2 / 3$ majority), and $\lambda=0.80$ ( $4 / 5$ majority).

The software package IRIS 2.0 (Dias and Mousseau, 2003) implementing the methodology in (Dias et al., 2002) was selected to obtain results for the models developed. One appealing characteristic of IRIS is that it does not require precise values for the criteria weights. It only assumes that weights are non-negative numbers and their sum is equal to 1 . It is possible to set intervals such as $w_{j} \epsilon[0$, 0.5 ] (for $j=1, \ldots, 10$ ), so that no criterion weighs more than all the rest, and then obtain the range of classes in which the alternatives can be sorted within these weight constraints. Initially (Section $3.2)$, results were obtained for this case and also considering other intervals $\left[w_{\text {inf }}, w_{\text {sup }}\right]$, established according to:

$\left\{\begin{array}{c}\frac{\left(w_{\text {inf }}+w_{\text {sup }}\right)}{2}=\frac{1}{n} \\ w_{\text {sup }}=\alpha \times w_{\text {inf }}\end{array} \Leftrightarrow\left\{\begin{array}{l}w_{\text {inf }}=\frac{2}{n(1+\alpha)}=\frac{1}{n}-\frac{\alpha-1}{n(1+\alpha)} \\ w_{\text {sup }}=\frac{2 \alpha}{n(1+\alpha)}=\frac{1}{n}+\frac{\alpha-1}{n(1+\alpha)}\end{array}\right.\right.$

Here, $\alpha$ represents the maximum acceptable ratio between any two weights (we obtained results for $\alpha=3, \alpha=5$, and $\alpha=10$ ). These intervals have a clear rationale: their bounds are such that their midpoint corresponds to the situation with equal weights $1 / n$ and the maximum weight cannot be greater than $\alpha$ times the minimum weight. For instance, setting $\alpha=10$ ensures $w_{i} / w_{j} \leq 10$ $(i, j=1, \ldots, n)$. An analysis with additional constraints is also reported (Section 3.3).

Table 3. Normalized indicator values.

\begin{tabular}{|c|c|c|c|c|c|c|c|c|}
\hline & IN & Indicator & Gasoline & Diesel & $\mathrm{HEV}$ & PHEV10 & PHEV40 & $\mathrm{BEV}$ \\
\hline \multirow{6}{*}{$\underset{\unlhd}{త}$} & 1 & $\mathrm{AD}$ (Abiotic depletion) & 0.83 & 0.74 & 0.75 & 0.60 & 0.70 & 0.60 \\
\hline & 2 & AC (Acidification) & 0.80 & 0.74 & 0.95 & 0.68 & 0.90 & 0.74 \\
\hline & 31 & EUT (Eutrophication) & 0.97 & 1.03 & 1.08 & 1.26 & 2.13 & 2.59 \\
\hline & & GW (Global warming) & 0.82 & 0.73 & 0.74 & 0.56 & 0.65 & 0.50 \\
\hline & & OLD (Ozone layer depletion) & 0.77 & 0.69 & 1.26 & 2.11 & 7.59 & 0.26 \\
\hline & $6 \mathrm{I}$ & PO (Photochemical oxidation) & 0.88 & 0.61 & 0.93 & 0.75 & 0.82 & 0.43 \\
\hline \multirow{4}{*}{$\begin{array}{ll}\frac{0}{0} & \frac{0}{0} \\
\frac{\pi}{0} & 0 \\
& 0 \\
\end{array}$} & $7 \mathrm{I}$ & FC (Fuel consumption) & 0.76 & 0.67 & 0.65 & 0.35 & 0.21 & 0.00 \\
\hline & $8 \mathrm{I}$ & $\mathrm{NO}_{\mathrm{x}}$ & 0.13 & 0.75 & 0.13 & 0.06 & 0.03 & 0.00 \\
\hline & 9 & $\mathrm{CO}$ & 0.69 & 0.46 & 0.69 & 0.31 & 0.18 & 0.00 \\
\hline & & PM (Particulate matter) & 0.90 & 0.93 & 0.90 & 0.57 & 0.45 & 0.30 \\
\hline
\end{tabular}




\section{Results}

\subsection{Normalized results and their interpretation}

Table 3 presents the normalized results of each alternative in the respective indicator. Each indicator is identified by a numeric label (IN, column 1) and an acronym (column 2). Normalized values above 1 represent a worse performance than the average vehicle in the reference scenario. For instance, the OLD value for the HEV, 1.26, indicates that this new HEV has $26 \%$ more lifecycle impacts in this indicator than an average vehicle in the reference fleet. The values before normalization can be reconstituted using Table 2, e.g., the OLD impact for the HEV is $1.26 \times 2.75 \times 10^{-5} \mathrm{~g} \mathrm{CFC}-11 \mathrm{eq}=3.47 \times 10^{-5} \mathrm{~g} \mathrm{CFC}-11$ eq. Most normalized impacts however are less than 1, which for the gasoline vehicle happens for all indicators. This means that one km travelled by the new gasoline vehicle has fewer impacts than one $\mathrm{km}$ travelled by a 2011 fleet vehicle on average (which includes cars built much before 2011 still operating at that time).

The HEV and both PHEV are the alternatives with the worst performance in more indicators (two indicators: EUT and OLD), when compared with the reference scenario (values above 1). Gasoline is the alternative with better performance than the average fleet vehicle in more indicators (values below 1 for all indicators) followed by Diesel and BEV (all indicators except one). If all vehicles in the fleet were replaced by the new BEV, vehicle impacts in all indicators would be significantly reduced, except EUT, where impacts would more than double. The 2011 fleet has a residual number of HEV, PHEV and BEV, which means much lower potential impacts per km than these alternatives in terms of EUT and OLD.

\subsection{Classification of the alternatives with ELECTRE TRI}

Table 4 shows the results of the vehicle classification derived by the application of ELECTRE TRI using IRIS. Cells in grey represent the classes to which each alternative can be assigned considering the indicator weight intervals. These conclusions are robust in the sense that only these classifications are possible given the constraints on the weights. If there is more than one grey cell for a given alternative, this means that some of the acceptable weight vectors (within the defined intervals) place it in one class, whereas some other acceptable weight vectors place it in another class. The range of possible classes is therefore reduced when the weight intervals are narrowed. Dashed cells represent intermediate classes that do not correspond to a possible assignment (for details see Dias and Mousseau, 2003). Table 4 depicts the results for a situation without veto and a situation with a veto threshold set for the best class, as described in Section 2.3. The grey cells marked with " $v$ " represent the classes that can be reached only if no veto threshold is applied. The grey cells with an asterisk represent the classes that are reached only if the veto threshold is applied.

Gasoline and Diesel are always classified in $C^{4}$ or $C^{5}$. For the Gasoline vehicle all the normalized impacts are better than $b^{3}=1$ (profile to reach $C^{4}$ ) and worse than $b^{5}=0.5$ (profile to reach $C^{6}$ ), with the exception of $\mathrm{NO}_{\mathrm{x}}$. However, the weight of a single criterion within the specified intervals cannot, on its own, justify a better classification (the maximum weight allowed in these analysis was 0.5 , whereas the minimum threshold used was $\lambda=0.51$ ). The Diesel vehicle normalized impacts 
also lie between $b^{3}=1$ and $b^{5}=0.5$, with the exception of EUT (which places it in $C^{3}$ ) and $C O$ (which places it in $\mathrm{C}^{6}$ ).

For $w \in[0,0.5]$, PHEV10, PHEV40 and BEV can reach $\mathrm{C}^{1}$ but also $\mathrm{C}^{6}$ (without veto threshold), depending on the indicator weights. These alternatives cannot reach $\mathrm{C}^{6}$ if the veto threshold is considered, due to poor performances in indicator 3 (EUT). EUT impacts are related to the consumption of electricity produced from coal. PHEV10 and PHEV40 also have significant impacts in OLD, which would by itself also veto classification in $\mathrm{C}^{6}$, due to the production phase of the lithium iron phosphate $\left(\mathrm{LiFePO}_{4}\right)$ battery. The difference between these alternatives in some parameter combinations is related to the different battery weight (PHEV10 battery weighs $23 \%$ of the PHEV40 battery). BEV has a different battery, a lithium manganese oxide $\left(\mathrm{LiMn}_{2} \mathrm{O}_{4}\right)$ battery; for this reason, its veto threshold is related only to EUT.

Table 4. Results derived by IRIS for different weight intervals and cutting levels.

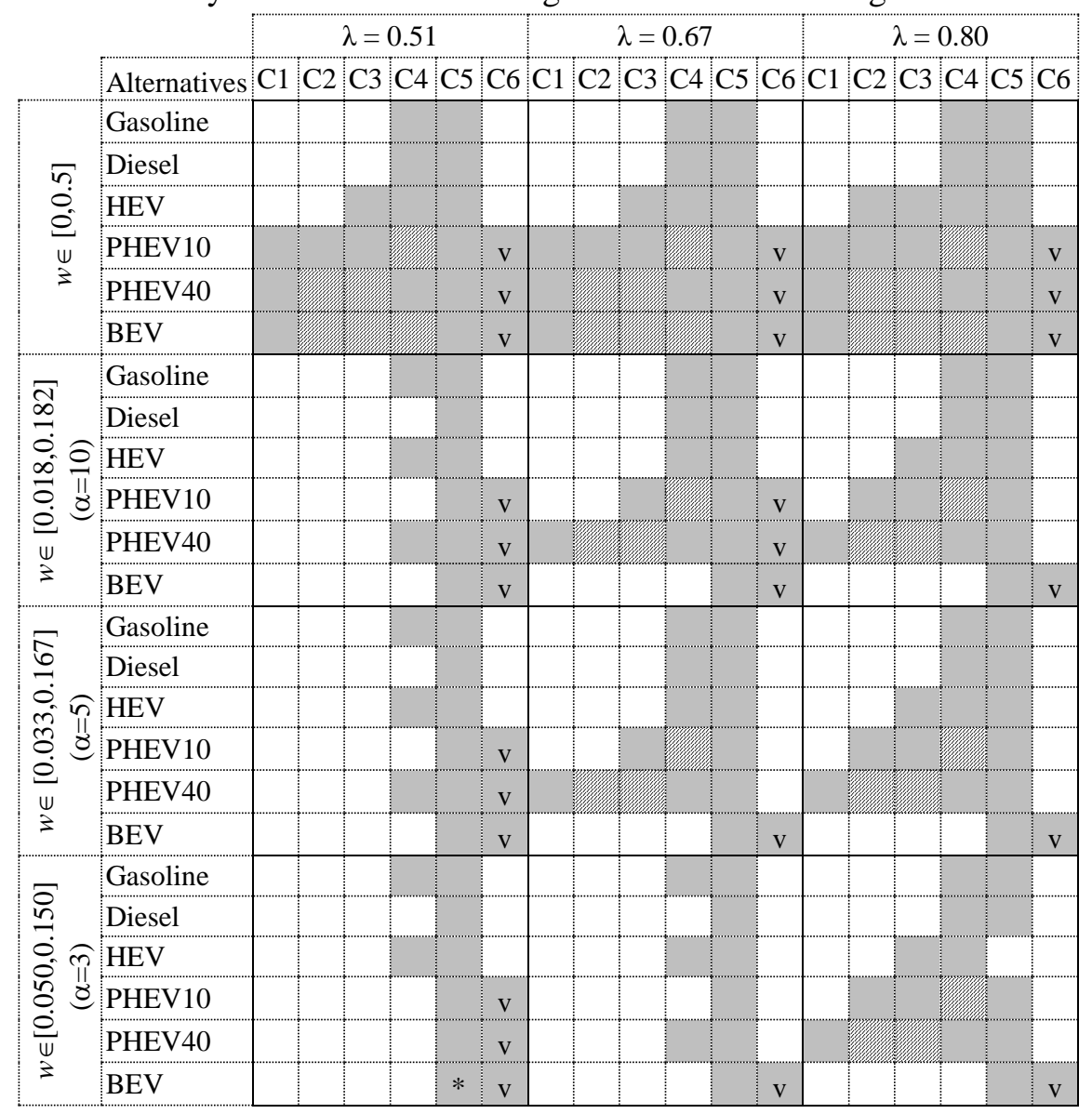

\subsection{Constraints on number of criteria supporting an outranking}

The ELECTRE TRI results presented in the previous section assume the weights are free to vary within the specified weight intervals. The IRIS software allows a decision maker to place further constraints on the classification results. Such constraints can reflect the concerns of a decision making entity, such as stating that indicator $X$ cannot have less weight than indicator $Y$. This section 
illustrates the use of a type of constraints which is more neutral (in the sense that all criteria are treated equally): specifying that a given number of criteria have sufficient weight to warrant an outranking conclusion, in the absence of veto.

In Table 4 some vehicles can be assigned to class $C^{1}$. On closer examination, it is possible to observe that this happens in situations in which only two indicators vote to place the alternative in this class. When enough freedom is allowed to choose the weight vectors, it is possible to assign enough weight for these two criteria that prevents the sum of the remaining criteria weights from attaining the cutting level $\lambda$.

A decision maker may be willing to state that any coalition of eight (out of the ten) indicators, no matter which, should have enough weight to warrant outranking, in the absence of a veto. This condition can be inserted in IRIS as weight constraints, yielding the results in Table 5 . The results for $\alpha=10$ are very similar to results for $\alpha=5$. Under this constraint, if $\lambda=0.8$ then all weights are forced to be equal to 0.1 , and for this reason a situation with $\lambda=0.75$ is presented.

Table 5. Results derived by IRIS for different weight intervals and cutting levels, if any coalition of eight criteria has weight at least as high as the cutting level $\lambda$.

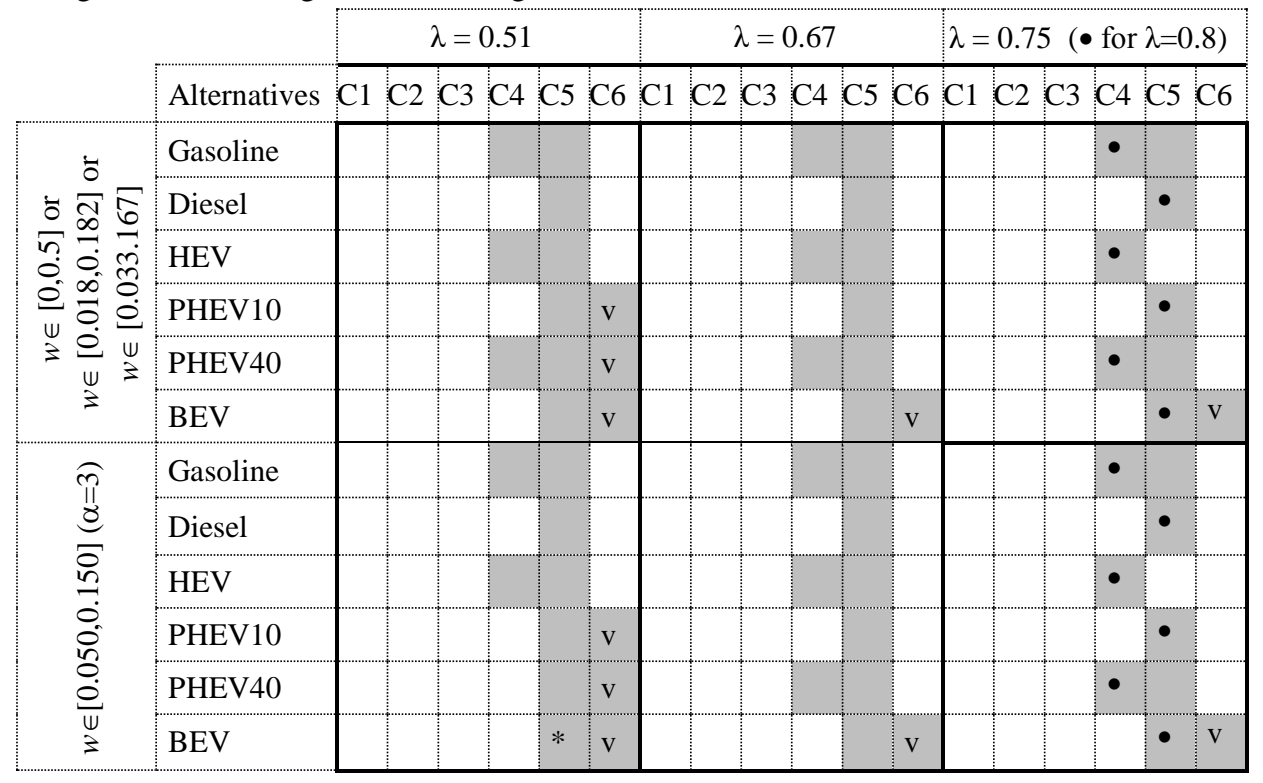

With this requirement that a coalition of eight indicators warrants an outranking, the Diesel vehicle is robustly sorted in $\mathrm{C}^{5}$, and the same happens for PHEV10 and BEV if the veto threshold is applied. Gasoline, HEV and PHEV40 can also be sorted in $\mathrm{C}^{5}$, but some weight vectors would place them in $\mathrm{C}^{4}$. The BEV and possibly the PHEV10 and the PHEV40, (if $\lambda=0.51$ ) may reach $\mathrm{C}^{6}$ for $\lambda<0.8$ but only if the veto threshold for the best class is not used.

\subsection{Analysis with different reference profiles}

The analyses reported in the previous sections provided results without making strong assumptions on the importance of each criterion. The only parameters required were: $\alpha$ (which specifies how different may such weights be) and $\lambda$ (which specifies how much of a majority is required). 
Nevertheless, the results depend on other parameters, namely the reference profiles that define the boundaries of the classes.

A decision making entity can choose not only the class boundaries, but also the number of classes, as inputs to ELECTRE TRI. The results presented in Sections 3.2 and 3.3 considered that the boundaries of the classes were $b^{5}=0.5, b^{4}=0.8, b^{3}=1, b^{2}=1.2$, and $b^{1}=1.5$, which define six classes. According to these results, the vehicles analyzed would not be classified in classes below $\mathrm{C}^{4}$, except for a few cases presented in Section 3.2. This is due to the fact that these are new vehicles that reduce the impacts of the 2011 fleet in most indicators.

This section analyses a setting in which there are seven classes, in which only the worst class $\left(\mathrm{C}^{1}\right)$ corresponds to performances worse than the 2011 reference. Classes $\mathrm{C}^{2}$ to $\mathrm{C}^{7}$ correspond thus to increasingly improved impacts, allowing a higher level of detail compared with the results in Sections 3.2 and 3.3. The reference profiles defining the class boundaries are now: $b^{6}=0.5, b^{5}=0.6$, $\mathrm{b}^{4}=0.7, \mathrm{~b}^{3}=0.8, \mathrm{~b}^{2}=0.9$, and $\mathrm{b}^{1}=1$.

Table 6. Results considering the second set of class profiles.

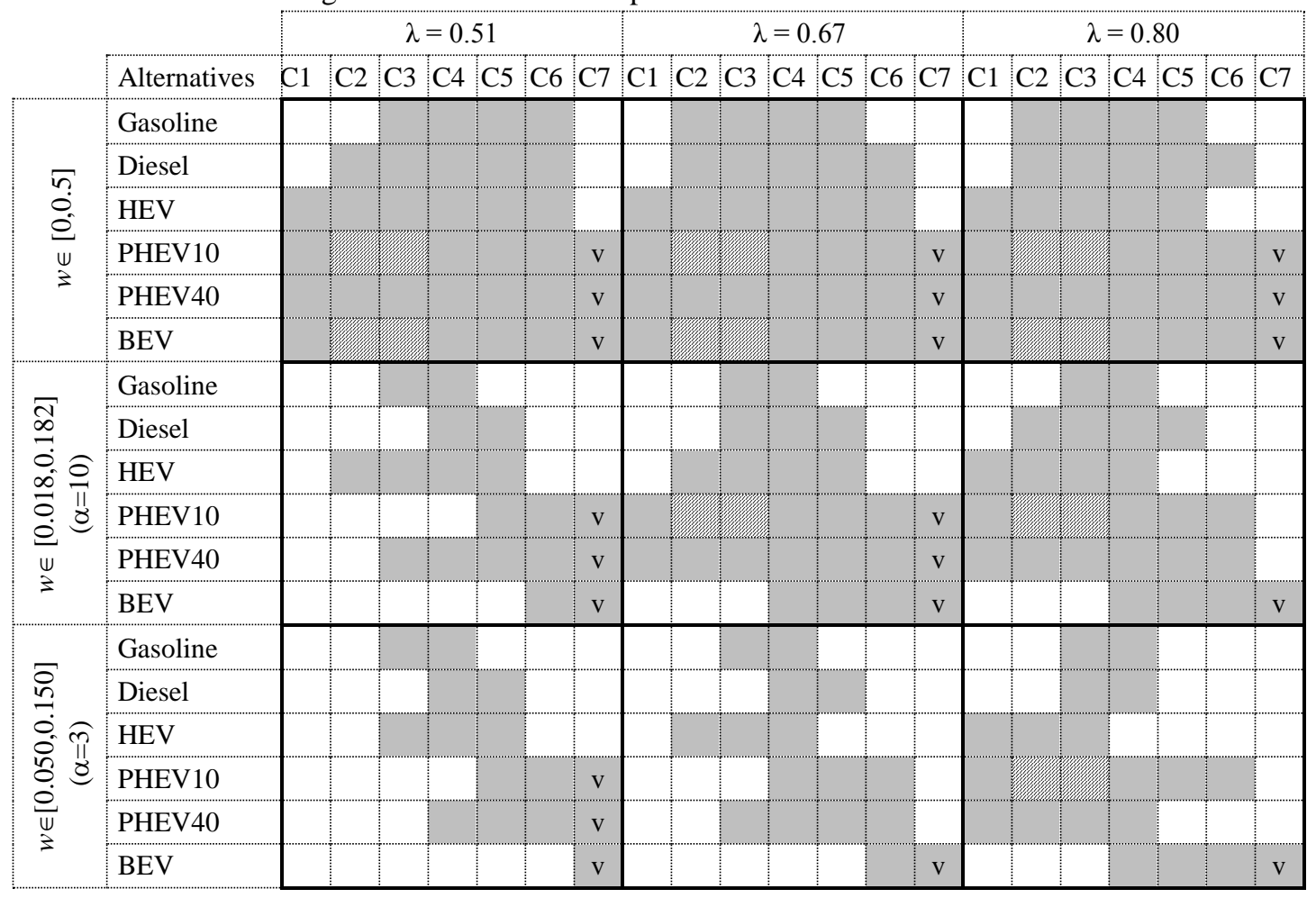

Considering the new set of classes, the results corresponding to Table 4 in Section 3.2 are depicted in Table 6 (for brevity, results concerning $\alpha=5$ are omitted). If, as in Section 3.3, one considers that any coalition of eight (out of the ten) indicators, no matter which, should have enough weight to warrant outranking in the absence of veto, then some of the classifications would no longer be possible, yielding the results depicted in Table 7 .

Comparing Table 5 and Table 7, it is evident that the latter set of results, corresponding to a more detailed classification, allows a greater differentiation of the vehicles. Considering these new 
reference profiles, the BEV could still reach the best class if no veto threshold is applied. If eight criteria are enough to warrant an outranking, and if a weight majority of $\lambda=0.67$ is required, then the two PHEV could reach at best class $\mathrm{C}^{6}$ and the remaining vehicles would at most achieve class $C^{5}$.

Table 7. Results considering the second set of class profiles, if any coalition of eight criteria has weight at least as high as the cutting level $\lambda$.

\begin{tabular}{|c|c|c|c|c|c|c|c|c|c|c|c|c|c|c|c|c|c|c|c|c|c|}
\hline & & \multicolumn{7}{|c|}{$\lambda=0.51$} & \multicolumn{6}{|c|}{$\lambda=0.67$} & \multicolumn{7}{|c|}{$\lambda=0.75(\bullet$ for $\lambda=0.8)$} \\
\hline & Alternatives & $\mathrm{C} 1$ & $\mathrm{C} 2$ & C3 & $\mathrm{C} 4 \mathrm{C}$ & C5 C & C6 C & C7 & C1 C & $\mathrm{C} 2 \mathrm{C} 3$ & $3 \mathrm{C} 4$ & $+\mathrm{C} 5$ & C6 & C7 & $\mathrm{C} 1$ & $\mathrm{C} 2$ & C3 & $\mathrm{C} 4$ & C5 & C6 & C7 \\
\hline \multirow{6}{*}{ 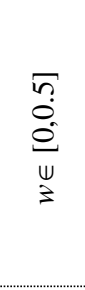 } & Gasoline & & & & & & & & & & & & & & & & $\bullet$ & & & & \\
\hline & Diesel & & & & & & & & & & & & & & & & & • & & & \\
\hline & HEV & & & & & & & & & & & & & & & $\bullet$ & & & & & \\
\hline & PHEV10 & & & & & & & $\mathrm{v}$ & & & & & & & & & & $\bullet$ & & & \\
\hline & PHEV40 & & & & & & & $\mathrm{v}$ & & & & & & & & & $\bullet$ & & & & \\
\hline & $\mathrm{BEV}$ & & & & & & & $\mathrm{v}$ & & & & & & $\mathrm{v}$ & & & & & & $\bullet$ & $\mathrm{v}$ \\
\hline \multirow{6}{*}{ 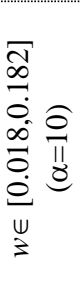 } & Gasoline & & & & & & & & & & & & & & & & $\bullet$ & & & & \\
\hline & Diesel & & & & & & & & & & & & & & & . & & $\bullet$ & & & \\
\hline & HEV & & & & & & & & & & & & & & & $\bullet$ & & & & & \\
\hline & PHEV10 & & & & & & & & & & & & & & & & & $\bullet$ & & & \\
\hline & PHEV40 & & & & & & & & & & & & & & & & $\bullet$ & & & & \\
\hline & $\mathrm{BEV}$ & & & & & & & $\mathrm{v}$ & & & & & & $\mathrm{v}$ & & & . & & & $\bullet$ & $\mathrm{v}$ \\
\hline \multirow{6}{*}{ 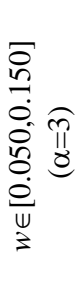 } & Gasoline & & & & & & & & & & & & & & & & $\cdot$ & & & & \\
\hline & Diesel & & & & & & & & & & & & & & & & & $\bullet$ & & & \\
\hline & HEV & & & & & & & & & & & & & & & $\bullet$ & & & & & \\
\hline & PHEV10 & & & & & & & & & & & & & & & & & $\bullet$ & & & \\
\hline & PHEV40 & & & & & & & & & & & & & & & & $\bullet$ & & & & \\
\hline & $\mathrm{BEV}$ & & & & & & & $\mathrm{v}$ & & & & & & $\mathrm{v}$ & & & & & & $\bullet$ & $\mathrm{v}$ \\
\hline
\end{tabular}

\section{Discussion and conclusions}

In this article, LCA was combined with MCDA to assess environmental impacts of six vehicles (with different powertrains) available in Portugal. The outranking method ELECTRE TRI was applied to LCIA and vehicle operation results.

The BEV assessed is the alternative with best performance in eight (out of ten) indicators. In particular, this BEV has the best performance in the four indicators related with the vehicle operation phase, which assess urban area air pollution (tailpipe and tire abrasion emissions) and oil dependency. Without veto threshold, PHEV10, PHEV40 and BEV are the only alternatives that can be considered much better than the average vehicle in the reference scenario (the 2011 PT lightduty fleet) even with the most demanding parameter settings.

$\mathrm{GW}$ is often the only indicator evaluated in the literature; however, other indicators should not be neglected. The results indicate that to reach the best class, BEV and PHEV need to reduce EUT and OLD life-cycle impacts. Concerning EUT, it is essential to increase the share of renewable or low carbon energy sources in the electricity mix and decrease the use of coal for energy production in 
order to maximize the environmental benefits of electric vehicles. The PHEV should use batteries that have lower impacts in OLD than the current battery $\left(\mathrm{LiFePO}_{4}\right)$.

MCDA results are influenced by the values selected for its parameters. Among these, the class profiles, the weights, the cutting level, and the veto threshold are the parameters with greatest influence in ELECTRE TRI results. The definition of the reference profiles determines how much it is possible to discriminate between vehicles in the results. The definition of the cutting level allows a decision maker to control how demanding the requirements are to reach the best classes. The results presented in this paper considered three levels of increasing requirement adjusting the cutting level $\lambda$ : simple majority, 2/3 majority, 3/4 majority or 4/5 majority. The veto threshold further allows controlling the minimum requirements on each individual indicator to access the top classes. To illustrate this, two variants were analyzed (with and without veto). The weights allow the decision maker to define the relative "voting power" of the different indicators. Rather than considering equal weights or committing to any precise weight values, this analysis considered that weights were free to vary within different intervals.

The methodology proposed in this paper intends to be neutral with respect to the importance of the indicators. This does not mean all indicators necessarily have the same weight (which would already be a value judgment): it simply means that all indicators must satisfy the same constraints. The idea of constraining weights within intervals is used to avoid that one indicator would have much more weight than some other indicator. Even considering one indicator can weigh ten times as much as some other ( $\alpha=10$, an order of magnitude), the range of results that are possible can already be very informative.

An emerging trend that avoids setting criteria weights is the stochastic exploration of weight spaces rather than using point values (Prado-Lopez et al., 2014). This entails specifying stochastic distributions for the weights (usually a uniform distribution) and deriving the corresponding result distributions using simulation techniques (Tervonen and Lahdelma, 2007). The approach followed in this paper uses point values but does not require that a decision maker sets an exact weights vector; the point values are chosen by an optimization algorithm in order to find (in an exact way) the best possible and the worst possible classes for each alternative, given a set of constraints. Hence, the robustness of the conclusions is guaranteed, without requiring any assumptions about the stochastic distribution for the weights. On the other hand, the stochastic approaches have the advantage of providing additional information, for instance, indicating the probability of each class for each alternative (Tervonen et al., 2009).

The price of not committing to a precise vector of indicator weights is to have intervals of classes as a result, rather than a crisp classification into a single class. If the entity performing the classification requires that each vehicle is assigned to a single class then there are (at least) two possibilities. The first possibility is to assign each vehicle to the best possible class in the resulting range. This can be interpreted as a "benefit of doubt" perspective (Cherchye et al., 2007), in which each vehicle would be classified using the weights (satisfying constraints) that would be most favorable to it, which would be different from vehicle to vehicle. The second possibility is to select one vector of weights within the allowed intervals. A third possibility is to assign each vehicle to the worst possible class in the resulting range. 
Assuming a benevolent "benefit of doubt" perspective of sorting each alternative on its best possible class all vehicles are classified as $C^{5}$ with the constraints in Section 3.2 and considering veto thresholds, for instance considering $\lambda=0.67$. The same occurs if the constraints presented in section 3.3 are added, again considering veto thresholds. If the more discriminating reference profiles are considered instead (Section 3.4), then choosing $\alpha=10$ and $\lambda=0.67$ would place the Gasoline vehicle in $C^{4}$, the Diesel and the HEV in $C^{5}$, the PHEV10 and PHEV40 in $C^{6}$, and the $\mathrm{BEV}$ in $\mathrm{C}^{6}$ or $\mathrm{C}^{7}$, depending on whether veto is considered or not, respectively.

A classification entity could find this to be a starting point for a continuous assessment of the vehicles. Every year, the normalization reference would be updated: for the next year, the normalization reference would be the 2012 fleet instead of the 2011 fleet, and so on. Therefore, vehicles would need to improve to achieve a better class, or even to maintain their current classification. Indeed, as newer and cleaner vehicles replace older vehicles in the fleet, the average impact of each $\mathrm{km}$ travelled will be lower. Thus, for instance, a vehicle with impacts $50 \%$ lower than an average vehicle in the 2011 fleet on some indicator may no longer have impacts $50 \%$ lower than an average vehicle in the 2014 fleet, and therefore no longer be considered in class $\mathrm{C}^{6}$ on that indicator.

The use of MCDA has been bringing new perspectives into traditional LCA, increasing its comprehensiveness and providing new ways of communicating results, instead of presenting a list of performance indicators for the considered alternatives. This work contributes to the literature on combining MCDA and LCA by proposing the use of a classification method, ELECTRE TRI, by proposing to use constraints on preference-related parameters, rather than demanding exact values, and by proposing a robustness analysis, i.e., the examination of the range of results compatible with the constraints provided. The constraints are such that can be easily understood and accepted by decision makers, since they do not involve value judgment that could be considered unwarranted. Another contribution is the examination of the vehicles used as a case study. This allowed identifying the indicators responsible for the main environmental impacts of some vehicles, namely in which indicators BEV and PHEV needed to decrease environmental impacts in order to achieve the best class. One must note, however, that these are six particular vehicles that do not represent all other vehicles with the same types of powertrain, and the Portuguese electricity mix is also not representative of the realities of other regions in the world.

\section{Acknowledgments}

The authors gratefully acknowledge support by the FCT/FEDER Programs (COMPETE MIT/MCA/0066/2009, PTDC/SEN-TRA/117251/2010) and project EMSURE (CENTRO 07-0224FEDER-002004). Rita Garcia thanks FCT for support under grant SFRH/BD/51299/2010. The authors are grateful to the subject editor and the anonymous reviewers, who provided detailed and valuable remarks which contributed to significantly improve the paper.

\section{References}

Arena, M., Azzone, G., Conte, A., 2013. A streamlined LCA framework to support early decision making in vehicle development. J. Clean. Prod. 41, 105-113. 
Belton, V., Stewart, T., 2002. Multiple Criteria Decision Analysis. An Integrated Approach. Kluwer, Boston.

Bouwman, M.E., Moll, H.C., 2002. Environmental analyses of land transportation systems in The Netherlands. Transp. Res. Part D Transp. Environ. 7, 331-345.

Ceuster, G.D., Herbruggen, B. V., Ivanova, O., Carlier, K., Martino, A., Fiorello, D., 2007. TREMOVE Service contract for the further development and application of the transport and environmental TREMOVE model Lot 1 (Improvement of the data set and model structure), Final Report.

Cherchye, L., Moesen, W., Rogge, N., Van Puyenbroeck, T., 2007. An introduction to "benefit of the doubt" composite indicators. Soc. Indic. Res. 82, 111-145.

Dahlbo, H., Koskela, S., Pihkola, H., Nors, M., Federley, M., Seppälä, J., 2012. Comparison of different normalised LCIA results and their feasibility in communication. Int. J. Life Cycle Assess. 18, 850-860.

Dangelico, R.M., Pontrandolfo, P., 2010. From green product definitions and classifications to the Green Option Matrix. J. Clean. Prod. 18, 1608-1628.

DAT, 2014. Guideline for fuel consumption, CO2 emission and electric power consumption of all New Passenger Car Models, offered for Sale on the German Market.

Dias, L., Mousseau, V., 2003. IRIS: a DSS for multiple criteria sorting problems. J. Multi-Criteria Decis. Anal. 12, 285-298.

Dias, L., Mousseau, V., Figueira, J., Clímaco, J., 2002. An aggregation/disaggregation approach to obtain robust conclusions with ELECTRE TRI. Eur. J. Oper. Res. 138, 332-348.

Dias, L.C., Domingues, A.R., 2014. On multi-criteria sustainability assessment: Spider-gram surface and dependence biases. Appl. Energy 113, 159-163.

Elghali, L., Cowell, S.J., Begg, K.G., Clift, R., 2006. Special Issue Honouring Helias A . Udo de Haes : LCA and Other Assessment Tools Support for Sustainable Development Policy Decisions A Case Study from Highway Maintenance. Int. J. Life Cycle Assess. 1, 29-39.

European Comission, 2009. Directive 2009/28/EC of the European Parleament and of the Council of 23 April 2009 on the promotion of the use of energy from renewable sources and amending and subsequently repealing Directives 2001/77/EC and 2003/30/EC.

Figueira, J., Mousseau, V., Roy, B., 2005. ELECTRE methods, in: Figueira, J., Greco, S., Ehrgott, M. (Eds.), Multiple Criteria Decision Analysis: State of the Art Surveys. Springer, pp. 133-153.

Finnveden, G., Hofstetter, P., Bare, J., Basson, L., Ciroth, A., Mettier, T., Seppala, J., Johansson, J., Norris, G., Volkwein, S., 2002. Normalisation, in: Udo de Haes, H. A.; Finnveden, G.; Goedkoop, M.; Hauschild, M.; Hertwich, E. G.; Hofstetter, P.; Jolliet, O.; Klopffer, W.; Krewitt, W.; Lindeijer, E.; Muller-Wenk, R.; Olsen, I.; Pennington, D. W.; Potting, J.; Steen, B. (Ed.), Life-Cycle Impact Assessment: Striving towards Best Practice. SETAC Press, Pensacola, FL.

Freire, F., Marques, P., 2012. Electric Vehicles in Portugal : an integrated energy, greenhouse gas and cost life-cycle analysis. IEEE Int. Symp. Sustain. Syst. Technol. $1-6$.

Garcia, R., Freire, F., 2013. A Fleet-based Life-cycle Assessment of Electric Vehicles in Portugal, in: Energy for Sustainability 2013. Sustainable Cities: Designing for People and the Planet, 8-10 September. Univ. Coimbra / ITeCons, Coimbra, Portugal. 
Garcia, R., Gregory, J., Freire, F., 2015. Life-cycle greenhouse gas emissions of displacing internal combustion engine vehicles by electric vehicles in the Portuguese passenger car fleet, in: Energy for Sustainability 2015 - Designing for People and the Planet, May 14-15. Univ. Coimbra / ITeCons, Coimbra.

Garcia, R., Marques, P., Freire, F., 2014. Life-cycle assessment of electricity in Portugal. Appl. Energy 134, 563-572.

Gaudreault, C., Samson, R., Stuart, P., 2009. Implications of choices and interpretation in LCA for multicriteria process design: de-inked pulp capacity and cogeneration at a paper mill case study. J. Clean. Prod. 17, 1535-1546.

Geldermann, J., Rentz, O., 2005. Multi-criteria Analysis for Technique Assessment: Case Study from Industrial Coating. J. Ind. Ecol. 9, 127-142.

Guinée, J.B., Heijungs, R., Huppes, G., Kleijn, R., de Koning, A., van Oers, L., Wegener Sleeswijk, A., Suh, S., Udo de Haes, H.A., de Bruijn, H., van Duin, R., Huijbregts, M.A.J., Gorrée, M., 2002. life cycle assessment. Operational guide to the ISO standards. I: LCA in perspective. IIa: Guide. IIb: Operational annex. III: Scientific background, The Netherlands: Ministry of .... Kluwer Academic Publishers, Dordrecht.

Hawkins, T.R., Gausen, O.M., Strømman, A.H., 2012. Environmental impacts of hybrid and electric vehicles—a review. Int. J. Life Cycle Assess. 17, 997-1014.

Heijungs, R., Guinée, J., Kleijn, R., Rovers, V., 2007. Bias in normalization: Causes, consequences, detection and remedies. Int. J. Life Cycle Assess. 12, 211-216.

Hermann, B.G., Kroeze, C., Jawjit, W., 2007. Assessing environmental performance by combining life cycle assessment, multi-criteria analysis and environmental performance indicators. J. Clean. Prod. 15, 17871796.

Huang, I.B., Keisler, J., Linkov, I., 2011. Multi-criteria decision analysis in environmental sciences: ten years of applications and trends. Sci. Total Environ. 409, 3578-94.

Infante, C.E.D.D.C., Mendonça, F.M. De, Purcidonio, P.M., Valle, R., 2013. Triple bottom line analysis of oil and gas industry with multicriteria decision making. J. Clean. Prod. 52, 289-300.

ISO, 2006. ISO 14044: Environmental Management - Life Cycle Assessment - Principles and Framework.

Jeswani, H.K., Azapagic, A., Schepelmann, P., Ritthoff, M., 2010. Options for broadening and deepening the LCA approaches. J. Clean. Prod. 18, 120-127.

Khalili, N.R., Duecker, S., 2013. Application of multi-criteria decision analysis in design of sustainable environmental management system framework. J. Clean. Prod. 47, 188-198.

Kiker, G.A., Bridges, T.S., Varghese, A., Seager, T.P., Linkov, I., 2005. Application of Multicriteria Decision Analysis in Environmental Decision Making. Integr. Environ. Assess. Manag. 1, 95-108.

Kim, J., Yang, Y., Bae, J., Suh, S., 2012. The Importance of Normalization References in Interpreting Life Cycle Assessment Results. J. Ind. Ecol. 00, 1-11.

Liu, Y., Liu, Y., Chen, J., 2014. The impact of the Chinese automotive industry: scenarios based on the national environmental goals. J. Clean. Prod. (in print). 
Ma, H., Balthasar, F., Tait, N., Riera-Palou, X., Harrison, A., 2012. A new comparison between the life cycle greenhouse gas emissions of battery electric vehicles and internal combustion vehicles. Energy Policy 44, 160-173.

Marques, P., Garcia, R., Freire, F., 2013. Life cycle Assessment of Electric and Conventional Cars in Portugal, in: Energy for Sustainability 2013. Sustainable Cities: Designing for People and the Planet. 8 10 September 2013, Coimbra, Portugal.

Mohamadabadi, H.S., Tichkowsky, G., Kumar, A.Ã., 2009. Development of a multi-criteria assessment model for ranking of renewable and non-renewable transportation fuel vehicles. Fuel 34, 112-125.

Myllyviita, T., Holma, A., Antikainen, R., Lähtinen, K., Leskinen, P., 2012. Assessing environmental impacts of biomass production chains - application of life cycle assessment (LCA) and multi-criteria decision analysis (MCDA). J. Clean. Prod. 29-30, 238-245.

Myllyviita, T., Leskinen, P., Seppälä, J., 2014. Impact of normalisation, elicitation technique and background information on panel weighting results in life cycle assessment. Int. J. Life Cycle Assess. 19, 377-386.

Nanaki, E.A., Koroneos, C.J., 2013. Comparative economic and environmental analysis of conventional, hybrid and electric vehicles - the case study of Greece. J. Clean. Prod. 53, 261-266.

Narayanan, D., Zhang, Y., Mannan, M.S.Ã., 2007. Engineering for sustainable development (ESD) in biodiesel production. Process Saf. Environ. Prot. 85, 349-359.

Notter, D. a, Gauch, M., Widmer, R., Wäger, P., Stamp, A., Zah, R., Althaus, H.-J., 2010. Contribution of Liion batteries to the environmental impact of electric vehicles. Environ. Sci. Technol. 44, 6550-6.

Ou, X., Yan, X., Zhang, X., Liu, Z., 2012. Life-cycle analysis on energy consumption and GHG emission intensities of alternative vehicle fuels in China. Appl. Energy 90, 218-224.

Perimenis, A., Walimwipi, H., Zinoviev, S., Miertus, S., 2011. Development of a decision support tool for the assessment of biofuels. Energy Policy 39, 1782-1793.

Prado-Lopez, V., Seager, T.P., Chester, M., Laurin, L., Bernardo, M., Tylock, S., 2014. Stochastic multiattribute analysis (SMAA) as an interpretation method for comparative life-cycle assessment (LCA). Int. J. Life Cycle Assess. 19, 405-416.

Rogers, K., Seager, T.P., 2009. Environmental Decision-Making Using Life Cycle Impact Assessment and Stochastic Multiattribute Decision Analysis : A Case Study on Alternative Transportation Fuels. Environ. Sci. Technol. 43, 1718-1723.

Rowley, H. V, Peters, G.M., Lundie, S., Moore, S.J., 2012. Aggregating sustainability indicators: beyond the weighted sum. J. Environ. Manage. 111, 24-33.

Roy, B., 1991. The Outranking Approach and the Foundations of Electre Methods. Theory Decis. 49-73.

Roy, B., 1996. Multicriteria Methodology for Decision Aiding. Kluwer Academic, Dordrecht.

Samaras, C., Meisterling, K., 2008. Life cycle assessment of greenhouse gas emissions from plug-in hybrid vehicles: implications for policy. Environ. Sci. Technol. 42, 3170-6.

Santoyo-Castelazo, E., Azapagic, A., 2014. Sustainability assessment of energy systems: integrating environmental, economic and social aspects. J. Clean. Prod. 80, 119-138. 
Seppälä, J., Basson, L., Norris, G.A., 2002. Decision Analysis frameworks for Life-Cycle Impact Assessment. J. Ind. Ecol. 5, 45-68.

Smith, W.J., 2010. Can EV (electric vehicles) address Ireland's CO2 emissions from transport? Energy 35, 4514-4521.

Soares, S.R., Toffoletto, L., Deschênes, L., 2006. Development of weighting factors in the context of LCIA. J. Clean. Prod. 14.

Spielmann, M., Bauer, C., Dones, R., Tuchschmid, M., 2007. Transport Services. ecoinvent report No.14. Dubendorf.

Tan, R.R., Culaba, A.B., Purvis, M.R.I., 2004. POLCAGE 1 . 0 - a possibilistic life-cycle assessment model for evaluating alternative transportation fuels. Environ. Model. Softw. 19, 907-918.

Tervonen, T., Lahdelma, R., 2007. Implementing stochastic multicriteria acceptability analysis. Eur. J. Oper. Res. 178, 500-513.

Tervonen, T., Linkov, I., Figueira, J.R., Steevens, J., Chappell, M., Merad, M., 2009. Risk-based classification system of nanomaterials. J. Nanoparticle Res. 11, 757-766.

Tsoukiàs, A., 2007. On the concept of decision aiding process: An operational perspective. Ann. Oper. Res. $154,3-27$.

Van Vliet, O., Brouwer, A.S., Kuramochi, T., van den Broek, M., Faaij, A., 2011. Energy use, cost and CO2 emissions of electric cars. J. Power Sources 196, 2298-2310.

Yagcitekin, B., Uzunoglu, M., Karakas, A., Erdinc, O., 2013. Assessment of electrically-driven vehicles in terms of emission impacts and energy requirements: a case study for Istanbul, Turkey. J. Clean. Prod. $1-7$.

Yu, W., 1992. ELECTRE TRI: Aspects méthodologiques et manuel d'utilisation. Document du LAMSADE. Université de Paris-Dauphine. Working Paper $n^{\circ} 74$, Paris.

Zackrisson, M., Avellán, L., Orlenius, J., 2010. Life cycle assessment of lithium-ion batteries for plug-in hybrid electric vehicles - Critical issues. J. Clean. Prod. 18, 1519-1529.

Zhou, Z., 2007. Life cycle sustainability assessment of fuels. Fuel 86, 256-263.

Zopounidis, C., Doumpos, M., 2002. Multicriteria classification and sorting methods: A literature review. Eur. J. Oper. Res. 138, 229-246. 